\title{
What makes it likeable? A study on the reactions to messages in a digital social network: the case of Facebook in Farsi
}

\author{
Shaho Sabbar ${ }^{1,3^{*}}$ and Daiwon Hyun ${ }^{2}$
}

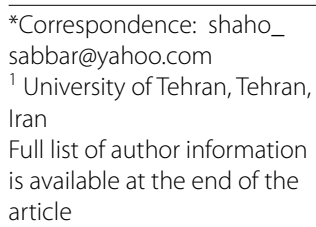

\begin{abstract}
Background: After a piece of information is put into a network, its fate depends on the behaviors of the nodes of the network; nodes that are equipped with the hardware and software of the age of information and are more powerful than any time in the past. This study suggests that a useful research for communication, marketing and advertising would be one that looks for patterns in the reactions of the nodes toward different pieces of information.

Results: This study has used Facebook to see how people have reacted to different types of messages in terms of liking, sharing and commenting. Rather than looking for universal, generalizable patterns we have tried to examine the practicality of the proposed method. The practical aspect of the study comes after a short theoretical discussion on the issue of flow of information in a digital world. The results revealed dozens of significant relations between the examined variables.
\end{abstract}

Conclusions: This study, its theoretical discussion and results suggest that it would be practical to study the relations between the characteristics of Facebook messages and the type of reactions (liking, sharing and commenting) that they attract.

Keywords: Flow of information, Network behaviors, Social network, Message, Reactions, Facebook

\section{Background}

The age of powerful nodes

Today social media are ubiquitously used by individuals (Peters et al. 2013) and the internet is considered as an important source of growth for many companies (Hoffman and Novak 2009). More than $70 \%$ of organizations around the world used social media in 2011 (KPMG 2011) and now nearly 90\% of U.S. companies use them (eMarketer 2014). Internet as a cheap and accessible tool is increasingly becoming a source of information (Ratchford 2015).

Moreover, marketing strategy has experienced significant changes by social media (Varadarajan and Yadav 2009). Websites such as Facebook, Linkedin, and MySpace have attracted the attention of marketers and more attention is dedicated to computer-mediated social environments (aka CMSEs) (Yadav et al. 2013). However companies might be still experiencing how to effectively use social media for their benefit (Shankar and Batra 
2009). In fact, we haven't been able to fully utilize the potentials of the new environment (Rydén et al. 2015) and regarding flow of information on Social Media, we have only started to understand the existing patterns and processes (Hennig-Thurau et al. 2010).

What is important for marketers here is people engagement (Pan and Chiou 2011; Schamari and Schaefers 2015; Deightona and Kornfeld 2009). After a message is released in a network by an original distributor (e.g. a mass medium) it's up to the nodes of the network how to react to it. The collective network behavior of the nodes determines where the message goes, how far it goes, and how long it stays. The spread of information by online word-of-mouth is an example of how information flows as a result of the actions of the nodes of a network (Berger and Iyengar 2013). In online and offline environments, many scholars who study word-of-mouth, fundamentally, work on how the actions of the nodes define the fate of pieces of information (Saenger et al. 2013; Heung 2008; Eisingerich et al. 2014).

The situation in which the nodes have the main role in the network flow of information is not new. It can be argued that when it comes to network flow of information, even in the offline world, nodes have always been the main actors. However, in a digital social network and an internet-enabled society the nodes have more power and a crucially more important role. Compared to the pre-internet times, the average node has links to a significantly higher number of nodes and its capacity of delivering messages in terms of number and volume has multiplied. Although some nodes may be more active and some may act as passive observers (Chandrashekaran et al. 2010).

Study has addressed the changed level of power of the individual actors in the network of audiences and consumers (Van Laer et al. 2013; Singh and Sonnenburg 2012; Gensler et al. 2013). While some have seen the emerging consumer power as a threat to companies and organizations (Hautz et al. 2014; Van Noort and Willemsen 2011) it is usually considered as an opportunity for businesses that can benefit from consumer engagement.

\section{The age of re-distribution}

Study has vastly addressed the abovementioned change (from the internet-free to the internet-enabled society), but another crucial change has happened in the dynamics of flow of information that has received less scholarly attention. In the past, after the initial transmission of a message, what would flow in the society would have been the perceptions of the nodes. One can imagine that in rare cases a person would read a story in a newspaper and make several photocopies of it and start giving the copies to others. However, the common scenario would be different: a person would read a story in a newspaper and start telling others about it. This is what long ago Lazarsfeld et al. (1944) explained as the two-step flow of information.

In fact, in the pre-internet era, if the dissemination of information had two stages, the first being media-to-people and the second being people-to-people or word-of-mouth (Batinic and Appel 2013), in the second stage, original messages were not the main things to be handed among the nodes. In the second stage, several different perceptions of the messages were shared and re-shared. In the time of the internet-based social networks this doesn't seem to be the case. The technologies of the age of digital social networks and especially the explosively fast spreading mobile devices (Shankar et al. 2010) have enabled the re-distribution of the original messages in a massive scale. 
If you are a member of a cellphone messaging system such as Viber, WhatsApp, Telegram, Kakao or the like, you may receive, on a daily basis, several pieces of audio, video, picture and text that were cut from a bigger content, previously published. These pieces of information may include a picture of the cover of a magazine, a piece of video cut from a TV program or a movie, an audio someone recorded at a debate at college, etc.

This adds to the importance of the role of the average members of the network as the contributors to creation and distribution of content. The number of people only in the U.S. who created content in 2013 estimated to be more than 110 million (Ertimur and Gilly 2012). Based on some estimates one out of four internet users are serious creators of content. Since in 2015 about 3.2 billion people used the internet (ITU 2015) there must have been some 800 million people who created digital content in that year. Users of Facebook alone share nearly 2.5 million pieces of content and email users send over 200 million messages per minute (Gunelius 2014).

The abovementioned changes have turned the average citizens to serious content creators and distributors (Nagao 2003). The possibility to take a message and re-distribute it in its original form, in a massive scale, is now there and it is being widely used by the normal nodes of our digital society. In this environment, the distribution of the materials produced by the media organizations and other major content creators depend on the decisions of the normal nodes of the network. We have tried in this paper to test a way of studying node decisions as a powerful force in the distribution of content in our digital network.

\section{Network behaviors}

Social networking sites have become a new social phenomenon that "is changing the way millions of people communicate and share information with each other" (VanMeter et al. 2015: 70). As argued above, an important stage of flow of information just begins after the initial distribution by the mass media and other mass content distributors. People take pieces of information from the original sources and redistribute them through social networks. These pieces of information are detached from the whole package of information originally distributed and in some cases the original source might even be unknown to most audiences.

In this process, people get to make very different decisions and show different network behaviors for every single piece of information. Cut two 1-min videos from a TV program that were aired one right after another. Then share them on a digital network. It would not be too surprising if one piece attracts no attention while the other is redistributed by thousands of the network members. This study is an effort to look into network behaviors of the nodes as factors that define the fate of messages in a network.

The concept of network behavior is similar to that of sequencing by Ying Mo and Wellman (2012) by which they mean the process of decision-making by the nodes during the flow of information. Scholars of marketing have also addressed the concept under the term of herding (Langley et al. 2014).

In marketing, which is about exposing the right person with the right message at the right time (Vilnai-Yavetz and Tifferet 2015) the behaviors of the nodes are studied, mostly within the study of viral marketing and word-of-mouth. In this field whatever affects the flow of information is critically important. If fact, "viral marketing has become a pivotal component of marketing strategy" (Koch and Benlian 2015:37) and computer-mediated 
word-of-mouth is sometimes considered as the most important marketing tool (Jiménez and Mendoza 2013; Goyette et al. 2010) especially with the development of Web2 (Hausmann 2012) and the expansion of social media that have provided word-of-mouth with an unparalleled platform to function (Chen et al. 2011).

Marketers are aware of the comparative importance of volunteer act of the nodes of a network in passing pieces of information, compared to diffusion of the messages using mass media (see Kaplan and Haenlein 2011; Pescher et al. 2014; Camarero and San José 2011). They are interested in putting out a message on the network and not worrying about the costs of distributing it, hoping that people would take care of the job and make the process of marketing affordable (Aksoy et al. 2013).

It would be an ideal world for a marketer in which he or she could look at a message and know what kinds of reactions it would receive from different nodes of the network. This study is a preliminary work in this area. We have proposed an approach based on studying the relations between the characteristics of the messages and the kinds of reactions they are more likely to receive.

\section{How to study reactions to materials}

Above, we discussed some changes in the role of the nodes of the network. We also argued that we should focus more attention on the network behavior of the nodes after they receive a piece of information. This general goal can be approached from many ways devised by the researchers. In fact the literature reviewed so far, is not specifically about the questions we are going to present in this study. In this section, we will review some studies that have asked questions related or similar to our research questions.

If the most important factor that defines the outcomes of a network is the collective network behaviors of the nodes, better knowledge and understanding about the behaviors of the nodes may enable us predict the fate of different pieces of information on the network. There is limited literature regarding the way one should systematically study the network behaviors of the nodes.

Choi and Toma (2014) in a study on Twitter posts found relations between the positivity of the posts and their likelihood to be shared. They say "highly intense positive events" had a better chance to be shared on Twitter than "low-intensity positive events". Interestingly they were able to study face-to-face relations too and concluded that "highly intense negative events" had a higher chance to be shared face-to-face than "lowintensity negative events".

Among different possible characteristics of online materials, Choi and Toma considered positivity and negativity and their relation to the network behaviors of the nodes (here sharing). However, there are many other characteristics that can be considered in a more detailed and comprehensive work. For instance, instead of the more general concept of positivity one could look into the materials being disappointing, nostalgic, emotional, comical, satirical, etc.

The abovementioned characteristics are mainly about the form of expression of the materials. However, the subject of materials can be also taken into consideration. In a research on Facebook Yu (2016) studied materials on Facebook and Twitter to see how 
political and non-political material were in relation to people's expressions. Subject of online material can include politics, economy, psychology, medicine, science, etc.

Fleuriet (2014) and her colleagues saw the characteristics of a Facebook post as "containing text only", "text plus either an attractive or unattractive photo of the sender", "a winking face emoticon", "words in all capitals", or "triple exclamation points". Then they studied how these different posts could affect the viewers emotionally.

In a study with a relatively similar approach to ours, Yu et al. (2011) used the same two sides of relation: the characteristics of Facebook posts-that they saw as content and media type-and the popularity of the messages-that they judged by the number of likes they received.

These studies linked the characteristics of online materials (political, positive, etc.) to how they were treated by people (shared, liked, and commented on). The two sides of relations are what the current study aims to investigate but in much more details.

Other studies have considered the characteristics of the node of the network. For instance Lee et al. (2014) looked into relations between personality traits such as being extravert, narcissist etc. with a series of actions on Facebook such as liking, sharing, frequency of updating their status, etc. The current study excludes the characteristics of the nodes in order to avoid over complication of the work.

\section{Objectives of the study}

At the moment that a message and a node meet, at least two factors can play role in defining the reaction: the characteristics of the node and the characteristics of the message. The current study has only taken the latter into consideration. Can we explain how a message would be treated in the network by studying its characteristics? This forms the questions of the study.

Facebook provides a practically helpful platform to perform such investigation. It's also one of the top three most visited websites of all (Hennig-Thurau et al. 2013). In this study a Facebook post published on a public page is considered as a message. Network behaviors are observed in two forms: (1) the number of times a Facebook post was liked (by pressing the like button) or it was shared (by pressing the share button) and (2) the type of comments that the Facebook users wrote on the posts.

Number one is about Facebook's predesigned ways of reacting to a post. Number two is about the way people react to a post by commenting on it. Comments are clearly more difficult to be studied than the number of shares and likes because one would need to go through a complicated process of coding and analysis to define different types of comments.

To be more specific about different types of comments we can categorize them to positive, negative, and neutral comments. Later it will be explained how we systematically classified user comments into more detailed categories. As for the Facebook posts, we would need to classify them into different types. Broadly speaking, this study classifies the posts based on their form, subject, form of expression, source, and the existence of praise and criticism. Later it will be explained how we categorized the Facebook posts into more detailed types. 
This study will look for significant relations between the type of messages on Facebook and the kind of reactions they would receive based on the general categories below (Fig. 1).

Q1: In a given Facebook society what characteristics of the posts in terms of form, subject, form of expression, source, and existence of praise and criticism are in significant relations with the number of times those posts are liked or shared?

The number of likes is important in the fate of the messages on Facebook for different reasons. A higher number of likes may be the indication of a higher attention to the post. Also when a post is liked it is automatically shown to other Facebook users, suggesting them to check out the post because their friend has liked it. Some studies have shown relations between the number of likes and people's attention to specific content e.g. loyalty to a brand (De Vries et al. 2012).

Studies in the field of marketing have shown positive relations between liking a brand on Facebook and brand evaluations (Beukeboom et al. 2015). If there are significant relation between some characteristics of Facebook posts and their higher chance of being liked by Facebook users, those characteristics could be very interesting for academicians. They can be also practically useful for marketers and advertisers as characteristics that help the message be seen by a larger number of people in the network.

Also if significant relations are found between the characteristics of the messages (here Facebook posts) and the number of times they are shared, one could try to use them to explain why some materials are shared more often than others. We do not expect that discovering any number of significant relations can enable us to fully explain or predict the number of times people would share a message. However, if we can find some relations, then one can argue that looking for this type of relations is a reasonable method to study the flow of different messages through a social network.




Q2: In a given Facebook society what characteristics of the posts in terms of form, subject, form of expression, source and existence of praise and criticism are in significant relations with positive, negative and neutral characteristics of the comments that are written on them?

Other than liking and sharing, people can choose what to write on a post as a comment. Both Facebook posts and the comments written on them by people can be defined by their characteristics. After that the relations between these sets of characteristics can be studied. In a broad sense the comments can be positive, negative or neutral. However, they can be classified based on more detailed characteristics which will be explained.

As an explorative study this research has questions rather than hypotheses. A hypothesis studies predicted relations between two specific variables. Explorative studies may study hundreds of relations between several variables. The current study will test some 1300 relations. Therefore, hypotheses are not appropriate for this study.

\section{Methods}

\section{Data gathering}

Possible audiences of a Facebook public page are the members of those pages. We looked for the most popular Facebook pages in terms of the number of their members and eventually chose 41 Farsi pages. Farsi is the language spoken mostly in Iran, Afghanistan and Tajikistan and the chosen pages were Iranian ones. This benefits the study at least in two ways.

First, it limits the number of popular pages and makes the selection possible. Second, even if there are significant relations between the characteristics of the messages and the reactions toward them, we cannot just assume those relations would be universal.

The probable relations can be specific to a network and its audiences. As an explorative research it would be better to limit the audiences to smaller geographical and cultural areas. Performing several studies on different societies and networks would enable future studies to draw out possible local and universal relations.

On Facebook pages, the admin or admins of the page post different messages and each message receives a specific number of likes, shares and comments. This study needs (1) the posts (in any format such as text, image or video), (2) the number of its likes and shares, as well as (3) the text of the comments people have written on them. In order to gather this data in a large scale a software application had to be designed.

We explained the idea to a professional computer programmer and asked him to code a software application that could collect Facebook posts and their related information. Once the application was ready we gave the URL of the 41 chosen pages to the application and it copied hundreds of thousands of the messages and comments on those pages. Later 591 posts and 770 comments were randomly chosen. Now it was time for the data to be processed and prepared for data analysis.

\section{Data processing}

The number of likes and shares that a Facebook post receives are countable variables. However, looking for significant relations between the characteristics of the messages and the characteristics of the comments written on them could be done only after we define such characteristics. 


\section{Characteristics of the messages (Facebook posts)}

We tried to define the characteristics of the messages with the help of two colleagues. We started observing many of the gathered messages and looked for any common attributes between the 591 posts in terms of form, subject, form of expression, source and the existence of praise and criticism.

Some characteristics were easy to see and define. For instance, some posts included a picture and some did not. Some included an advertisement while some didn't. Some characteristics were in common between many posts but they were not easy to define, such as being nostalgic. They needed to be discussed, studied and redefined by the research team. Once a first draft of the common attributes was proposed the list needed to be examined and redefined.

Three researchers cooperated in the long and challenging process of finding and defining the common characteristics of the posts. First by observing many messages a list of 64 characteristics were proposed with their preliminary definitions. Then the researchers coded a number of posts individually and after comparing the results they revised the operational definitions to make them more practical and less ambiguous.

This process was repeated several times until the difference between the results of the work of the researchers was less than $2 \%$. The leading researcher then made the final decision for the $2 \%$. Also 23 of the initially proposed characteristics were omitted from the list, either because their operational definitions could not get clear enough or because there were not enough cases in the chosen Facebook posts to lead to any statistically significant results.

Eventually the 591 Facebook posts were coded for having or not having any of 46 characteristics. This included making more than 27,000 decisions. Sometimes these decisions had to be made several times by the same or different coders in an attempt to provide reliable results.

Also Cohen's Kappa was calculated to insure interrater agreement and the reliability of the coding results.

$$
\mathrm{k}=(\operatorname{Pr}(\mathrm{a})-\operatorname{Pr}(\mathrm{e})) /(1-\operatorname{Pr}(\mathrm{e}))
$$

The calculated Kappa was over 0.86, which shows excellent interrater agreement.

The final characteristics are as follows:

Form links, texts, photos of famous people, pictures (excluding the photos of famous people), video clips, music.

Subject psychological issues, political issues, economic issues, religious (or anti-religious) issues, social and cultural issues, scientific issues, relations with the opposite sex, family relationships, environmental issues, literary materials, news, request for like or share, questions or request for comments.

Form of expression disappointing materials, warning, expression of sorrow or regret, emotional materials, spiritual emotions, advice, nostalgic materials, jokes, satire, poems 
or literature, insult, hopeful materials, reasoning and analysis, artistic materials, aphorism, advertisement.

Source quotes from famous people, quotes from religious texts, quotes from sources, personal opinions.

Praise admiration of the current politicians or political system of Iran, admiration of individuals.

Criticism criticism of individuals, criticism of a social group, criticism of the current politicians or political system of Iran, criticism of the politicians or political system of other countries, criticism of Iran or Iranians.

During the coding process, each characteristic was treated as an individual variable to be checked. For instance, coders did not ask themselves a question such as the following: Is this post political or economic? They would check the post to see if it contained economic issues regardless of their decision if it included political contents.

\section{Network Behavior of the Nodes (User comments on Facebook posts)}

The 770 comments were coded in a similar way to the process used for the posts. Similar to what was done before, we made sure coding process and its results were reliable. Cohen's Kappa being over 0.84, interrater agreement was proved to be reliably high.

The final list of characteristics of the network behaviors includes 24 items. Here we did not consider the types of issues (say economic, political, etc.) in defining the characteristics of the comments. Network behaviors are about the type of reactions. Reactions could be broadly categorized and positive, negative or neutral.

The final list of characteristics for the network behavior of the nodes is presented below.

Positive expressing agreement, defending the post against another commenter, expressing gratitude, expressing positive emotions.

Negative questioning the post, insulting the admin, blaming the admin for uploading such a post, insulting or making pungent remarks, showing partial disagreement.

Neutral adding to what was presented in the post, making recommendations, correcting the post's mistake, joking with the admin of the page, answering questions, raising a question or request, trying a game or enigma, answering a multiple choice question, inviting others to see the post, reacting to another commenter, reasoning and analysis, joking and making sarcastic comments, laughter, expressing emotions, advertising or irrelevant. 
This part of the coding process also included finding, defining and redefining the attributes and more than 20,000 instances of decision-making and they had to be done more than once. ${ }^{1}$

\section{Results}

In this section the results of the statistical analysis of the relations between the proposed sets of data will be reported.

\section{Results regarding the first question}

The first question concerns the relations between the characteristics of the Facebook posts and the number of likes and shares they received. To make the statistical analysis possible the posts had to be divided to at least two groups based on the number of likes and shares they received. If a post was liked by 1800 people or less it was coded as Low and if more than 1800 people liked a post it was coded as high. For this section of the study 491 posts were taken into consideration, among which 245 posts fell under the group with low number of likes, and 246 posts received high number of likes.

On Facebook the number of people who share a post is always less than those who like it. If a post was shared by 200 people or less, it was coded as Low. If more than 200 people shared a post it was coded as high. For this section of the study 470 posts were taken into consideration, ${ }^{2}$ among which 240 posts fell under the group with low number of times being shared and 230 posts fell under the group with high number of times being shared.

Statistical analysis of the relations between the number of people who liked and shared a Facebook post and the existence of any of the 46 characteristics resulted in 30 significant relations. Pearson's Chi-square test was used to see how significant the results were, and only the ones with a level of significance equal to or higher than $95 \%$ were reported. ${ }^{3}$ Many of the reported relations were much more than $95 \%$ reliable. These relations have been summarized in Table 1.

\footnotetext{
${ }^{1}$ In the recent years automated methods of text analysis including Linguistic Inquiry and Word Count (LIWC) have improved. Since the process of manually coding posts is extremely time-consuming, the current study was able to analyze a limited number of posts and comments which can be considered a limitation of the study. Automated methods have allowed research projects to consider large amounts of text and as a result have significantly improved generalizability of the studies.

The current research did not employ such automated systems for a number of reasons, as follows:

- While Farsi dictionaries have improved, the structure of the language makes it difficult to perform highly reliable automated works, especially on informal texts. In informal environments a significant number of words are written differently from their dictionary form.

- In informal English, he is going to becomes he's gonna. Such changes happen to almost every Farsi verb and the changes are major: bekhaaheem becomes bekhaaim and bekhaahand changes to bekhaan. Considering the intentional misspelling of words by very young generations (who tend to write only the one or two initial letters of the words) the problem is even more serious. This is why, although Farsi dictionaries have significantly improved and they are employed in many applications, when it comes to informal texting (such as in cell-phone conversations) they are next to useless.

- Farsi uses Perso-Arabic alphabet which is based on Arabic script. However, many Facebook users use English alphabet to type Farsi; similar to the sample Farsi words presented above to show how informal Farsi is written differently from formal Farsi. Farsi dictionaries do not work with the texts typed in this way, which is called Finglish (Farsi + English).

- In our analysis we also considered non-written characteristics of the posts such as photos.

- We tried to detect a long list of characteristics/types in the posts and comments such as aphorism, opinions, reasoning, spiritual emotions, etc. The existence of such features is very hard for a robot to detect.

2 The analyzed data was gathered using a software application. The application was not able to retrieve data regarding the number of likes and shares for over 100 of the selected posts.

3 To show the status of correlations between the variables in this study, we used Chi-square test. Here, Chi-square as a nonparametric test was used instead of parametric tests such as independent $t$ test. One reason for this is the fact that the variances between the two comparison groups were different. Also in this study we were dealing with non-normal distribution of data, and more importantly the variables were all nominal.
} 
Table 1 Significant relations between the characteristics of the posts and the number of likes and shares

\begin{tabular}{|c|c|c|c|c|}
\hline \multirow[t]{2}{*}{ Characteristics of the posts } & \multicolumn{4}{|l|}{ Facebook predesigned reactions } \\
\hline & Like & & Share & \\
\hline Form & & & $\begin{array}{l}\text { Pictures (excluding the photos } \\
\text { of famous people) }\end{array}$ & $40 \%$ \\
\hline \multirow[t]{5}{*}{ Subject } & $\begin{array}{l}\text { Questions or request for com- } \\
\text { ments }\end{array}$ & $-28 \%$ & $\begin{array}{l}\text { Questions or request for com- } \\
\text { ments }\end{array}$ & $-61 \%$ \\
\hline & Psychological issues & $-41 \%$ & $\begin{array}{l}\text { Religious (or anti-religious) } \\
\text { issues }\end{array}$ & $35 \%$ \\
\hline & Family relationships & $39 \%$ & Request for like or share & $-42 \%$ \\
\hline & Relations with the opposite sex & $50 \%$ & Social and cultural issues & $22 \%$ \\
\hline & Request for like or share & $-35 \%$ & Literary materials & $52 \%$ \\
\hline \multirow[t]{8}{*}{ Form of expression } & Satire & $55 \%$ & Jokes & $-50 \%$ \\
\hline & Advertisement & $-53 \%$ & Satire & $43 \%$ \\
\hline & Artistic materials & $44 \%$ & Advertisement & $-41 \%$ \\
\hline & Emotional materials & $42 \%$ & Nostalgic materials & $-44 \%$ \\
\hline & Reasoning and analysis & $-26 \%$ & Emotional materials & $23 \%$ \\
\hline & & & Advice & $30 \%$ \\
\hline & & & Reasoning and analysis & $30 \%$ \\
\hline & & & Disappointing materials & $31 \%$ \\
\hline \multirow[t]{3}{*}{ Source } & & & Personal opinions & $60 \%$ \\
\hline & & & Quotes from famous people & $41 \%$ \\
\hline & & & Quotes from sources & $30 \%$ \\
\hline Praise & Admiration of individuals & $32 \%$ & $\begin{array}{l}\text { Admiration of the current } \\
\text { politicians or political system } \\
\text { of Iran }\end{array}$ & $-66 \%$ \\
\hline Criticism & & & Criticism of Iran or Iranians & $79 \%$ \\
\hline
\end{tabular}

The table shows how existence of specific characteristics in the posts has increased or decreased the probability of receiving a high number of likes and shares. For instance, there was a significant relation between the existence of satire in the posts and the number of people who liked it. In 70.9\% of the cases where satire existed in the post, a high number of people pressed the Like button, while when it didn't exist, only in $45.7 \%$ of the cases high number of people did so.

This indicates that there was a direct relation between the existence of this characteristic in the post and its likelihood to receive likes from the people. The level of significance for Pearson's Chi-square test was more than $99.9 \%$. Table 1 presents the results in a different way. The existence of satire in the posts increased the probability of being liked by $55 \%$.

The existence of some characteristics had an invert effect on the probability of a post being liked. For instance, if analytical and reasoning-based materials existed in a post it had $26 \%$ less chance that its audiences pressed the like button. The rest of the numbers can be seen in the table.

The analyses aimed at answering the first question of the study show that characteristics related to the materials' subject, form of expression and existence of praise were in significant relations with the likelihood of the posts being liked. They also showed that the materials' form, subject, form of expression, source, and existence of praise and 
criticism were in significant relations with the likelihood of the posts being shared (Table 2).

\section{Results regarding the second question}

The second question concerns the relations between the characteristics of the Facebook posts and the characteristics of the comments written on them. The statistical analysis of the relations between these two sets of characteristics showed 105 significant relations, presented in Table 3.

Data presented in Table 3 show, in a similar way, how the probability of specific network behaviors can change with the existence of specific characteristics in the post.

For example as the table shows, there are at least 12 characteristics that their existence in a post increased the probability of expressing agreement by the commenter. And there are at least 3 characteristics that their existence in the post decreased such probability.

The results show that if there are quotes from famous people in the post the chance that people show agreement to the post in their comments increases by $50 \%$. For example if in the absence of quotes from famous people, $10 \%$ of the commenters expressed agreement, where quotes from famous people existed, $15 \%$ of the commenters expressed agreement.

Some of the numbers in the tables are more than 100 which make the results more interesting. For instance the existence of an advice in the post increased the chance that the commenters expressed gratitude by $310 \%$.

The existence of one characteristic in the post could have a relation with several behaviors. The table could be rearranged so that this is seen easier. Table 4 that was extracted from Table 3 shows all the behaviors that changed with the existence of a personal opinion .

When a personal opinion existed in the post, the probability that people showed agreement increased by $427 \%$ but at the same time the chance that the admin was blamed increased by $336 \%$ and the probability of partial disagreement increased by $359 \%$. Understandably personal opinions provoke controversy especially in polarized societies.

The 105 significant relations link form, subject, form of expression, source and the existence of praise and criticism in the Facebook posts with positive, negative and neutral comments written by the users. Table 5 shows what relations were observed between the abovementioned variables.

Table 2 Relations found between general types of messages and number of likes and shares

\begin{tabular}{lll}
\hline Facebook post & Facebook predesigned reactions \\
\cline { 2 - 3 } & Like & Share \\
\hline Form & & $\checkmark$ \\
Subject & $\checkmark$ & $\checkmark$ \\
Form of expression & & $\checkmark$ \\
Source & $\checkmark$ & $\checkmark$ \\
Praise & & $\checkmark$ \\
Criticism & & $\checkmark$ \\
\hline
\end{tabular}




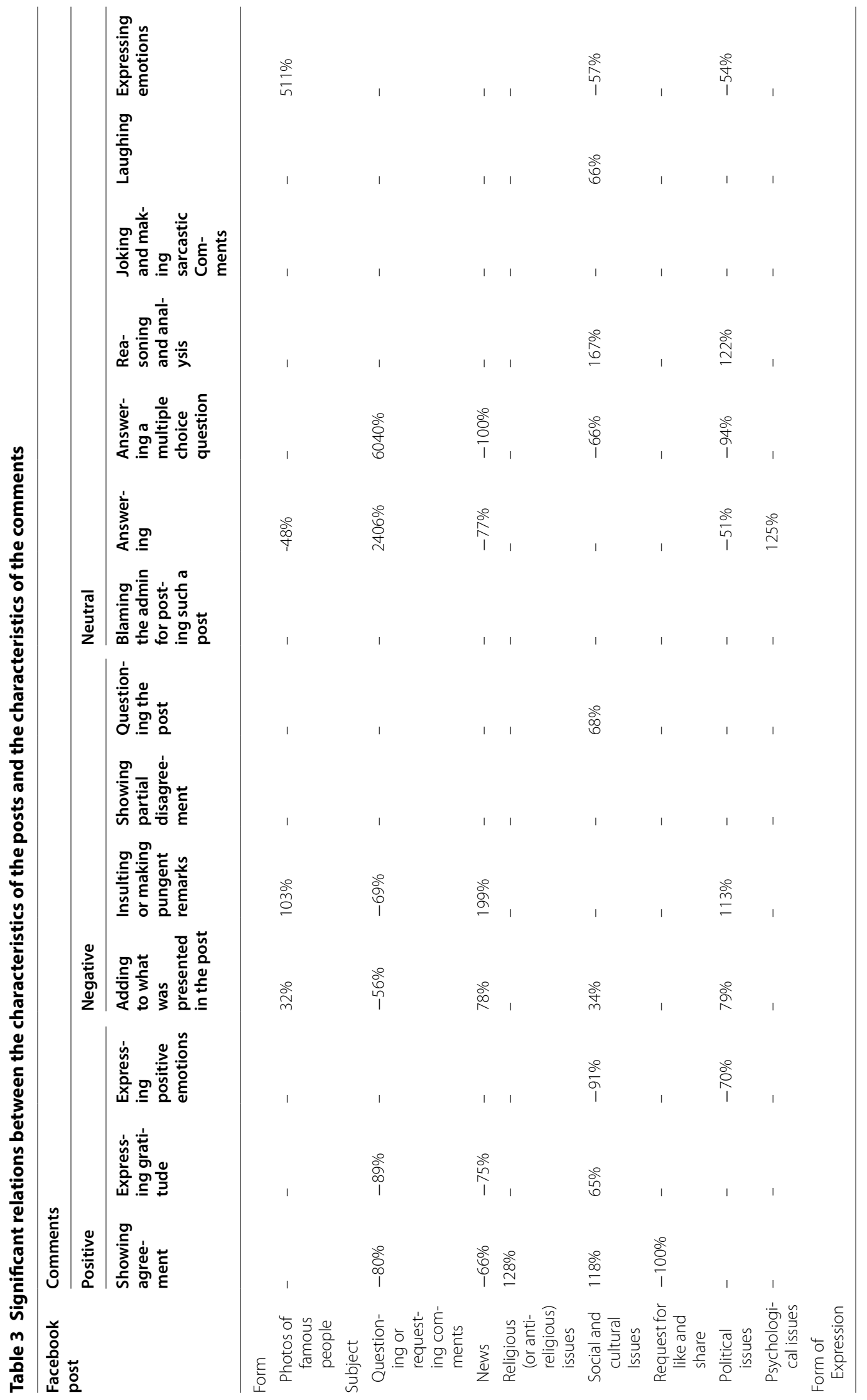









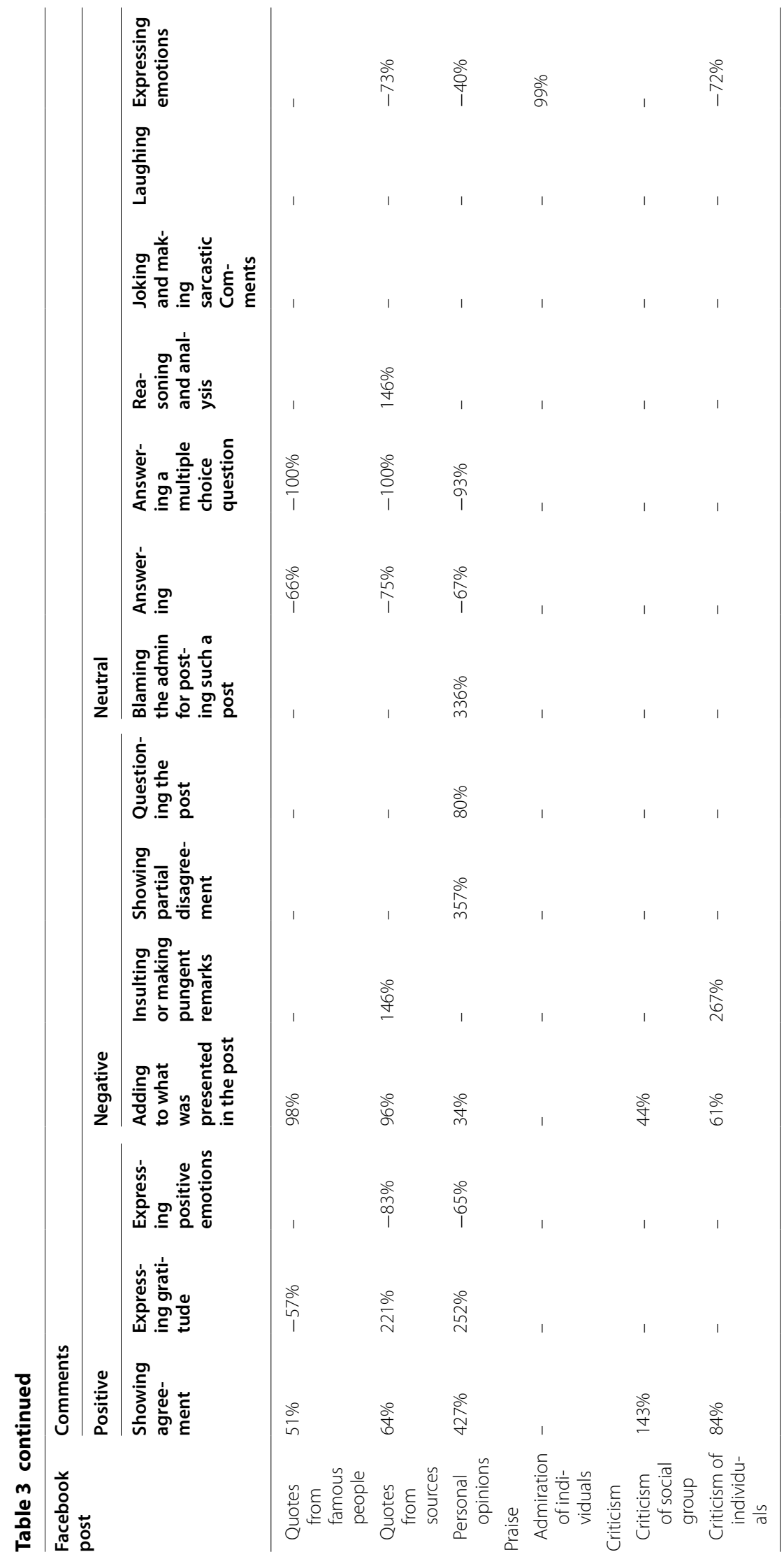


Table 4 Behaviors in significant relation with the existence of personal opinions in the post

\begin{tabular}{lr}
\hline Personal opinions & $\%$ \\
\hline Expressing agreement & 427 \\
Expressing gratitude & 252 \\
Adding to what was presented in the post & 34 \\
Answering & -67 \\
Expressing positive emotions & -65 \\
Expressing emotions & -40 \\
Showing partial disagreement & 357 \\
Questioning the post & 80 \\
Blaming the admin & 336 \\
\hline
\end{tabular}

Table 5 Relations found between general types of messages and types of comments

\begin{tabular}{|c|c|c|c|}
\hline & Commer & & \\
\hline & Positive & Negative & Neutral \\
\hline Form & & $\checkmark$ & $\checkmark$ \\
\hline Subject & $\checkmark$ & $\checkmark$ & $\checkmark$ \\
\hline Form of expression & $\checkmark$ & $\checkmark$ & $\checkmark$ \\
\hline Source & $\checkmark$ & $\checkmark$ & $\checkmark$ \\
\hline Praise & & & \\
\hline Criticism & $\checkmark$ & $\checkmark$ & $\checkmark$ \\
\hline
\end{tabular}

\section{Discussion}

The issue of hidden variables

Reviewing the results, we might find some relations hard to explain. For instance, one might ask: why should criticism of social groups increase the probability of expressing agreement from the commenter by almost $150 \%$. Is this result reliable? Two points should be noted in this regard.

1. The levels of significance are high but not a hundred.

In any research project in which hundreds of relations are statistically studied, no matter how high the level of significance is, a concern would be having few relations occurring by accident. For instance, if the average level of significance in this project is $98 \%$, out of 130 reported results 2 or 3 might be a result of chance rather than robust existing patterns.

The only way to find out whether or not there were such cases among the results, and if yes, which of the results were due to chance, is waiting for additional studies to provide us with a better understanding of the issue. However, it is unlikely that many false relations exist in the results.

2. Sometimes what is more important than why

The results indicate existing relations between two sets of variables and not causal relations between them. We cannot expect all the relations to seem predictable and 
understandable. Some of the significant results may be in consistence with what we already expect and for some of the results we may not have any explanations. This does not change the fact that there is a very high chance that those patterns are there and the first step to better understand them is to know they exist.

Even where we don't seem to understand a relation there may be very good explanations; however sometimes even knowing why a relation exists is not worthy of the effort needed to find it out. The reasons behind a relation between two variables can be very complicated and many factors may be engaged. Sometimes based on the projects' needs, rather than explaining why specific groups of people act in a specific way, we just need to know how they behave.

\section{The black box of human brain}

The behaviors studied here are the results of human reactions. When a person responses to the stimulus of a message, deep "underlying impulses" (Bandura 1971) can be involved in their reaction. To understand those underlying impulses studying human behavior, as well as, people's static attributes (say gender, age class, etc.) and dynamic attributes-say opinion, interest, etc.-(Bouanan et al. 2016) can be helpful.

Since the acquired information "serves as a guide for action" (Bandura 1974) deeper understanding of the interactions between people and information can be acquired through understanding people's psychology and behavior. Moreover, to better understand the reactions of the nodes in a network we need to understand their individual and social experiences; as people are "agents of experience" (Bandura 2001).

However, as mentioned before this study intentionally disregarded the characteristics of the human factor and instead looked at their reactions (Fig. 2).

In behavioral studies sometimes human brain is considered as a black box that we might not be aware of the processes within it. However, interaction between communication and behavioral studies can help us develop more comprehensive methods to investigate, understand and even predict human reactions in confrontation with different types of messages (Fig. 3).

\section{Conclusions}

Since this is an explorative work, trying to pave the way for future studies, at least parts of its results are general findings that can inspire future studies. However, it has very detailed and specific outcomes as well.

The main outcomes of the study can be introduced as follows:

1. By ignoring other factors and only studying the characteristics of the messages running within given communities on Facebook, researchers can find factors in significant relation with the number of times the messages are liked.

This might be true in other networks too. The results of the study indicate that it is worth the expenses and the effort to conduct large scale studies to see what characteristics in a message can attract more likes on Facebook or more attention on other networks. 


\section{(x)

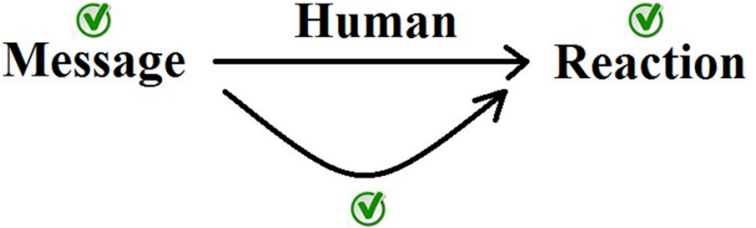

Fig. 2 Disregarding human factor in studying the relations between messages and reactions

\section{Black Box}

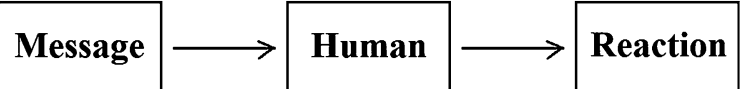

Fig. 3 Disregarding human factor in studying the relations between messages and reactions

2. It may be hard to generalize this to all communities within Facebook, but the results of the study among Iranian pages show that the following features, if existing in a Facebook message, had negative impact on its chance of receiving likes from the users:

- asking questions or requesting comments

- advertisements

- psychological issues

- request for like or share

- reasoning and analysis

On the other hand, the existence of the following features increased the chances of receiving likes by a Facebook post.

- satire

- artistic materials

- family relationships

- relationship with the opposite sex

- emotional materials

- admiration of individuals

We have also acquired numbers telling us how much the chances of receiving likes would increase or decrease. This information can have practical values for campaigners and companies. Also the results can be of value for those interested in conducting similar but more comprehensive/focused studies or studies among different communities.

3. Similar to what was mentioned in the outcome number 1 , we have shown that by exploring the characteristics of the messages we can find features increasing or decreasing their chances of being shared with others. In fact, the results of this study 
shows that the idea of calculating the probability of a message being distributed between people can have practical values.

4. Similar to what mentioned in the outcome number 2; we have a list of features that their existence in a message can increase or decrease its chances of being shared with others. We also have numbers showing to what extent those features can change the probabilities. Since the list has been already provided in tables, they will not be repeated here. This list can be used by campaigners, advertisers or researchers.

5. This study put forward the concept of network behaviors and argued that the characteristics of messages can define the way they are treated on a network and proposed that these relations could be studied in a detailed level. The fact that several significant relations were found between the types of Facebook materials and the way people reacted to them proves this approach practical.

Other studies can target specific networks, specific communities and specific types of materials (say brands, political issues, etc.) and use the method proposed in this research to study what characteristics can increase the probability of people reacting in desired ways.

6. We have found a long list of significant relations between the characteristics of the messages and the way people react to them. We also have numbers indicating how much a specific characteristic have increased or decreased the likelihood of a reaction. Campaigners, advertisers and researchers may pick specific characteristics and use them in their projects or studies.

As a preliminary work we tried to introduce a way to approach the study of flow of information in a digital social network and examine the practicality of that approach. Since several significant relations were drawn, it seems to be clear that this approach is practical and with several future studies, there would be hope to reach a point where we have a list of practical relations that tell us why different messages travel differently in the network.

To be ambitious maybe future works give us the power to predict the fate of a message if released in the network. In such an ideal situation we may be capable of predicting how long a message would keep moving before it stops reaching new people; how many people it would reach; what types of people it would reach, etc.

As mentioned before, neither network behaviors nor message characteristics had to be defined in the way we did in this study. Longer, more practical, socially more sensitive lists of characteristics and behaviors, proposed by future studies may result in much more practical guidelines for us to understand why specific messages travel in the network the way they do.

\section{Other applications}

Other than understanding how network flow of information works, information can be drawn from the results to better understand the society of Iranian Facebook users-if not generalizable, at least as clues for future studies. For instance the results show that disappointing materials have increased the probability of expressing agreement by $150 \%$. Also expression of sorrow or regret has increased the probability of showing agreement by $224 \%$. For a study focused on that society, this information may be meaningful. 
Also other studies-not concerned with flow of information-may use the method used in this study to understand people. Other scholars may develop ways of exploring people by analyzing their reactions to different types of content.

\section{Authors' contributions}

The study and the resulting article is a part of SS doctoral studies. He discussed the ideas with his advisor DH. Sabbar conducted the literature review, made the questionnaires and did major parts of the data gathering and data analysis. The final text is mainly written by him. DH contributed in developing the ideas and solving practical complications of the research. Both authors read and approved the final manuscript.

\section{Author details}

${ }^{1}$ University of Tehran, Tehran, Iran. ${ }^{2}$ Sogang University, Seoul, South Korea. ${ }^{3}$ Present Address: Faculty of World Studies, Northern Amir-Abad, 15th \& 16th streets, Tehran, Iran.

\section{Acknowledgements}

The authors would like to thank Professor Saied Reza Ameli and National Elites Foundation for their scientific guidance and precious advices on the research. We appreciate the help of Ms. Najmeh Mohammad-khani, Ms. Saeedeh Zadghannad and Ms. Saideh Ghaderi who spent tens of hours helping with the coding process. Mr. Shahin Soheili-Bakhsh designed and coded a software application that helped us with the data gathering process. His astonishing work is appreciated. Mr. Ebrahim Mohseni's consultant and help with the statistical analysis of the data were very constructive. The authors thank him. We would also like to thank Ms. Shekufeh Ranjbar for editing the manuscript and Ms. Sepide Alinoori for her constructive insights.

\section{Competing interests}

Both the authors declare that they have no competing interests.

\section{Consent/ethics}

Data were gathered through questionnaires. All the participants were informed (through the questionnaire) that answering the questions meant they accepted to be participants of the study. Also the study and its general goals were described in the questionnaires and the respondents were asked to provide the research with an email address if they wanted to receive the results of the study. Moreover, we did not have minor participants.

Received: 13 June 2016 Accepted: 30 November 2016

Published online: 20 December 2016

\section{References}

Aksoy L, Buoye A, Aksoy P, Larivière B, Keiningham TL (2013) A cross-national investigation of the satisfaction and loyalty linkage for mobile telecommunications services across eight countries. J Interact Mark 27:74-82

Bandura A (1971) Social learning theory. General Learning Press, New York

Bandura A (1974) Behavior theory and the models of man. Am Psychol 29:859-869

Bandura A (2001) Social cognitive theory: an agentic perspective. Ann Rev Psychol 52:1-26

Batinic B, Appel M (2013) Mass communication, social influence, and consumer behavior: two field experiments. J Appl Soc Psychol 43:1353-1368

Berger J, lyengar R (2013) Communication channels and word of mouth: how the medium shapes the message. J Consum Res 40:567-579

Beukeboom CJ, Kerkhof P, de Vries M (2015) Does a virtual like cause actual liking? How following a brand's Facebook updates enhances brand evaluations and purchase intention. J Interact Mark 32:26-36

Bouanan Y, Zacharewicz G, Vallespir B (2016) DEVS modelling and simulation of human social interaction and influence. Eng Appl Artif Intell 50:83-92

Camarero C, San José R (2011) Social and attitudinal determinants of viral marketing dynamics. Comput Hum Behav 27:2292-2300

Chandrashekaran M, Grewal R, Mehta R (2010) Estimating contagion on the internet: evidence from the diffusion of digital/information products. J Interact Mark 24:1-13

Chen Y, Fay S, Wang Q (2011) The role of marketing in social media: how online consumer reviews evolve. J Interact Mark 25:85-94

Choi M, Toma CL (2014) Social sharing through interpersonal media: patterns and effects on emotional well-being. Comput Hum Behav 36:530-541

De Vries L, Gensler S, Leeflang PSH (2012) Popularity of brand posts on brand fan pages: an investigation of the effects of social media marketing. J Interact Mark 26:83-91

Deightona J, Kornfeld L (2009) Interactivity's unanticipated consequences for marketers and marketing. J Interact Mark 23:4-10

Eisingerich AB, Auh S, Merlo O (2014) Acta non verba? The role of customer participation and word of mouth in the relationship between service firms' customer satisfaction and sales performance. J Serv Res 17:40-53

eMarketer (2014) Social marketing 2015: the key to ROI will come from within. Retrieved from eMarketer: http://www. emarketer.com/Article/Social-Marketing-2015-Key-ROI-Will-Come-Within/1011305

Ertimur B, Gilly MC (2012) So whaddya think? Consumers create ads and other consumers critique them. J Interact Mark 26:115-130 
Fleuriet CC (2014) Exploring Facebook: attachment style and nonverbal message characteristics as predictors of anticipated emotional Reactions to Facebook postings. J Nonverbal Behav 38(4):429-450

Gensler S, Völckner F, Liu-Thompkins Y, Wiertz C (2013) Managing brands in the social media environment. J Interact Mark 27:242-256

Goyette I, Ricard L, Bergeron J, Marticotte F (2010) e-WOM scale: word-of-mouth measurement scale for e-services context. Can J Adm Sci 27:5-23

Gunelius S (2014) The data explosion in 2014 minute by minute-infographic. Retrieved 16 Jan 2016, from ACl.info: http://aci.info/2014/07/12/the-data-explosion-in-2014-minute-by-minute-infographic/

Hausmann A (2012) Creating 'buzz': opportunities and limitations of social media for arts institutions and their viral marketing. Int J Nonprofit Volunt Sector Mark 17:173-182

Hautz J, Füller J, Hutter K, Thürridl C (2014) Let users generate your video ads? The impact of video source and quality on consumers' perceptions and intended behaviors. J Interact Mark 28:1-15

Hennig-Thurau T, Malthouse EC, Friege C, Gensler S, Lobschat L, Rangaswamy A et al (2010) The impact of new media on customer relationships. J Serv Res 13:311-330

Hennig-Thurau T, Hofacker CF, Bloching B (2013) Marketing the pinball way: understanding how social media change the generation of value for consumers and companies. J Interact Mark 27:237-241

Heung VC (2008) Effects of tour leader's service quality on agency's reputation and customers' word-of-mouth. J Vacat Market 14:305-315

Hoffman DL, Novak TP (2009) Flow online: lessons learned and future prospects. J Interact Mark 23:23-34

ITU (2015) ITU releases 2015 ICT figures_Statistics confirm ICT revolution of the past 15 years. Retrieved 19 Jan 2016, from ITU: http://www.tu.int/net/pressoffice/press_releases/2015/17.aspx\#.VsSQ3PJ96VN

Jiménez FR, Mendoza NA (2013) Too popular to ignore: the influence of online reviews on purchase intentions of search and experience products. J Interact Mark 27:226-235

Kaplan AM, Haenlein M (2011) Two hearts in three-quarter time: How to waltz the social media/viral marketing dance. Bus Horiz 54:253-263

Koch OF, Benlian A (2015) Promotional tactics for online viral marketing campaigns: how scarcity and personalization affect seed stage referrals. J Interact Mark 32:37-52

KPMG (2011) Going social—-how businesses are making the most of social media. KPMG International. https://www. kpmg.com/FR/fr/lssuesAndlnsights/ArticlesPublications/Documents/Going-social-how-business-are-making-themost-of-social-media.pdf. Retrieved 18 Jan 2016

Langley DJ, Hoeve MC, Ortt JR, Pals N, van der Vecht B (2014) Patterns of herding and their occurrence in an online setting. J Interact Mark 28:16-25

Lazarsfeld PF, Berelson B, Gaudet H (1944) The people's choice: how the voter makes up his mind in a presidential campaign. Columbia University Press, New York

Lee E, Ahn J, Kim YJ (2014) Personality traits and self-presentation at Facebook. Pers Individ Differ 69:162-167

Nagao K (2003) Digital content annotation and transcoding. Artech House, London

Pan L-Y, Chiou J-S (2011) How much can you trust online information? Cues for perceived trustworthiness of consumergenerated online information. J Interact Mark 25:67-74

Pescher C, Reichhart P, Spann M (2014) Consumer decision-making processes in mobile viral marketing campaigns. J Interact Mark 28:43-54

Peters K, Chen Y, Kaplan AM, Ognibeni B, Pauwels K (2013) Social media metrics-a framework and guidelines for managing social media. J Interact Mark 27:281-298

Ratchford BT (2015) Some directions for research in interactive marketing. J Interact Mark 29:v-vii

Rydén P, Ringberg T, Wilke R (2015) How managers' shared mental models of business-customer interactions create different sensemaking of social media. J Interact Mark 31:1-16

Saenger C, Thomas VL, Johnson JW (2013) Consumption-focused self-expression word of mouth: a new scale and its role in consumer research. Psychol Mark 30(11):959-970

Schamari J, Schaefers T (2015) Leaving the home turf: how brands can use webcare on consumer-generated platforms to increase positive consumer engagement. J Interact Mark 30:20-33

Shankar V, Batra R (2009) The growing influence of online marketing communications. J Interact Mark 23:285-287

Shankar V, Venkatesh A, Hofacker C, Naik P (2010) Mobile marketing in the retailing environment: current insights and future research avenues. J Interact Mark 24:111-120

Singh S, Sonnenburg S (2012) Brand performances in social media. J Interact Mark 26:189-197

Van Laer T, de Ruyter K, Cox D (2013) A Walk in customers' shoes: how attentional bias modification affects ownership of integrity-violating social media posts. J Interact Mark 27:14-27

Van Noort G, Willemsen LM (2011) Online damage control: the effects of proactive versus reactive webcare interventions in consumer-generated and brand-generated platforms. J Interact Mark 26:131-140

VanMeter RA, Grisaffe DB, Chonko LB (2015) Of "Likes" and "Pins": the effects of consumers' attachment to social media. J Interact Mark 32:70-88

Varadarajan R, Yadav MS (2009) Marketing strategy in an internet-enabled environment: a retrospective on the first ten years of JIM and a prospective on the next ten years. J Interact Mark 23:11-22

Vilnai-Yavetz I, Tifferet S (2015) A picture is worth a thousand words: segmenting consumers by facebook profile images. J Interact Mark 32:53-69

Yadav MS, de Valck K, Hennig-Thurau T, Hoffman DL, Spann M (2013) Social commerce: a contingency framework for assessing marketing potential. J Interact Mark 27:311-323

Ying Mo G, Wellman B (2012) Understanding sequencing in social network communications. Bull Méthod Sociol 113:76-87

Yu RP (2016) The relationship between passive and active non-political social media use and political expression on Facebook and Twitter. Comput Hum Behav 58:413-420

Yu B, Chen M, Kwok L (2011) Toward predicting popularity of social marketing messages. Lect Notes Comput Sci 6589:317-324 